\title{
Evaluation on the diagnostic and prognostic values of long non-coding RNA BLACAT1 in common types of human cancer
}

Xiaoli Chen ${ }^{1+}$, Meiyu Dai ${ }^{1+}$, Hongzhen Zhu ${ }^{1+}$, Jinwan $\mathrm{Li}^{1}$, Zhizhuo Huang ${ }^{1}$, Xuexiang Liu ${ }^{1}$, Yujie Huang ${ }^{1}$, Jingfan Chen ${ }^{2,3^{*}}$ and Shengming Dai ${ }^{1,3^{*}}$

\begin{abstract}
A growing number of evidence has indicated that long non-coding RNAs (IncRNA) may have many functions in the development and progression of cancer, and cloud serve as good diagnostic and prognostic biomarkers in cancers. However, these studies often revealed the changes of IncRNAs within a specific cancer type. Here, we focused on BLACAT1 and provided a comprehensive pan-cancer analysis to evaluate the diagnostic and prognostic values of BLACAT1. The expression data of BLACAT1 were came from the quantitative real-time polymerase chain reaction (qRT-PCR) and The Cancer Genome Atlas (TCGA) database, respectively. Our results showed that the change of serum BLACAT1 expression was similar to those in matched tissues. The expression level of BLACAT1 both in serum and tissues in multiple cancer types were significantly upregulated compared to those of matched non-cancer participants. The serum BLACAT1 had a high diagnostic performance among these 12 types of cancer. The relative AUC of serum BLACAT1 in cancer patients ranged from 0.833 to 0.967 compared to that in healthy subjects. Surprisingly, Kaplan-Meier survival analysis revealed that the high expression level of BLACAT1 was significantly associated with poor overall survival only in uterine corpus endometrial carcinoma ( $p=0.002$, log-rank test). These findings demonstrated that BLACAT1 could act as a non-specific diagnostic biomarker for cancers and a potential biomarker for prognosis prediction of endometrial cancer.
\end{abstract}

Keywords: Long non-coding RNA, BLACAT1, Cancer, TCGA, Diagnosis, Prognosis

\section{Background}

Although the advance in surgical techniques and chemoradiotherapy, cancer is still one of the diseases that threaten human beings' health and lives seriously. Blood-based tumor markers have always been a hot spot of research for diagnostic and prognostic markers as they are noninvasive and highly reproducible at low cost. Many molecular markers have been reported to predict the occurrence and treatment of cancer [1-3]. However, no specific or sensitive biomarkers have been confirmed

\footnotetext{
* Correspondence: 3203008361@qq.com; daishm@sina.com

†Equal contributors

2Department of General Surgery, the Fourth Affiliated Hospital of Guangxi Medical University, Liuzhou, Guangxi 545005, China

${ }^{1}$ Medical Science Laboratory, the Fourth Affiliated Hospital of Guangxi Medical University, Liuzhou, Guangxi 545005, China

Full list of author information is available at the end of the article
}

and used in clinical practice to predict the occurrence and outcome of cancer up to now. According to the systematically calculation from American Cancer Society, the sensitivity of a prostatic specific antigen cutoff of $4.0 \mathrm{ng} / \mathrm{mL}$ was $21 \%$ for detecting any prostate cancer (PC) and $51 \%$ for detecting high-grade cancers (Gleason 28) [4]. Liu et al. had reported that the sensitivity and specificity of the diagnostic marker carcinoembryonic antigen for colorectal cancer (CRC) were $46.1 \%$ and $89.2 \%$, respectively [5]. Serum alpha-fetoprotein, as a gold standard in hepatocellular carcinoma (HCC) detection, has low diagnostic accuracy, with sensitivities ranging from a mere $18-60 \%$ and a specificity of $\sim 85-90 \%$ [6].

Long non-coding RNAs (lncRNAs) have many functions in various pathophysiological processes [7-10]. 
The dysregulation of lncRNAs plays pivotal roles in many kinds of diseases, particularly in cancer [11-13]. The lncRNAs circulating in serum/plasma are relatively stable because they are not degraded by RNase even in the complex environment in vivo [14]. Thus, the lncRNAs could be acted as potential diagnostic or prognostic markers in multiple types of cancer [15-18]. BLACAT1, known as linc-UBC1, is found on human chromosome 1q32.1 and has a transcript of $2616 \mathrm{~kb}$ with just one exon [19]. It was firstly reported as a negative prognostic factor for lymph node metastasis and survival in bladder cancer (BLC) [20]. Our previous research has shown that BLACAT1 was upregulated in CRC tissues compared to adjacent normal tissues and could serve as a novel diagnostic biomarker [21]. However, these studies have just explored the clinical and biological significance in a specific cancer type. Thus, the diagnostic and prognostic values of BLACAT1 in many other cancer types are still unclear.

In this study, we evaluated the diagnostic value of serum BLACAT1 across 12 common types of cancers, and used RNA-seq datasets of The Cancer Genome Atlas (TCGA) to evaluate the prognostic value of BLACAT1 in 14 types of cancers. Our results showed that BLACAT1 could serve as a non-specific diagnostic marker for these types of cancer and prognostic marker only in endometrial cancer (EMC).

\section{Result}

Serum BLACAT1 could be served as a non-specific biomarker for the diagnosis in cancer

To test whether BLACAT1 was a specific biomarker for a specific cancer type, we used the qRT-PCR to measure 1080 serum samples in 12 common types of cancer and the corresponding benign lesions and healthy subjects (Additional file 1: Table S1). These 12 different types of cancer included: HCC, lung cancer (LC), breast cancer (BC), ovarian cancer (OC), EMC, cervical cancer (CC), $\mathrm{PC}$, gastric cancer (GC), esophagus cancer (EC), thyroid cancer (TC), BLC and nasopharynx cancer (NPC). For the diagnostic value of serum BLACAT1 in CRC was reported in our previous article, the CRC was not included in present study [21]. According to the qRT-PCR confirmation results, serum BLACAT1 was performed well in distinguishing cancer from healthy subjects in these 12 types of cancer, which was not able to distinguish cancer from benign lesions in $\mathrm{BC}, \mathrm{OC}, \mathrm{PC}$ and $\mathrm{NPC}$ (Additional file 1: Figure S1). To further investigate the diagnostic performance of serum BLACAT1, we then performed an ROC curve analysis. With significantly differentiated level in cancer subjects as compared with healthy subjects, the relative AUC of serum BLACAT1 in these 12 types of cancer was from 0.833 to 0.967 (Fig. 1). The diagnostic values of serum BLACAT1 in 12 types of cancer were summered in Table 1.

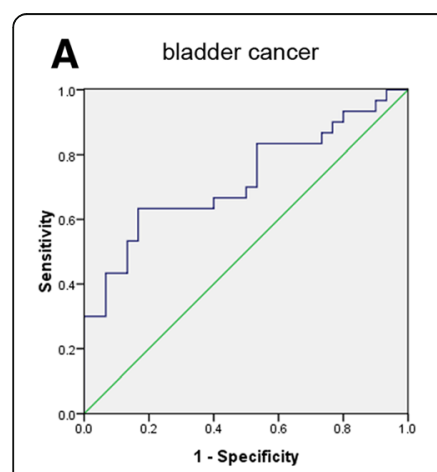

E gastric cancer

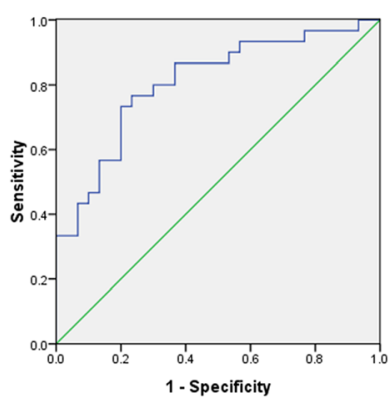

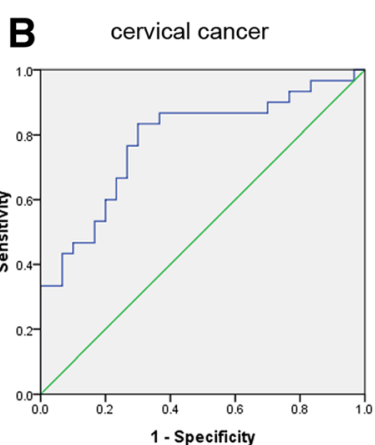

F hepatocellular carcinoma

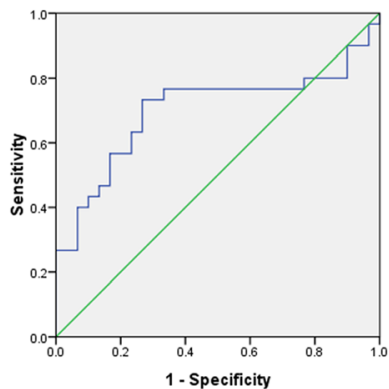

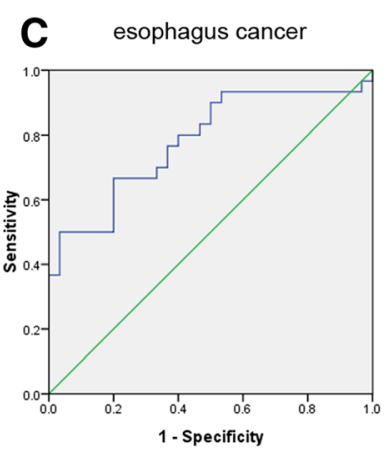

G lung cancer

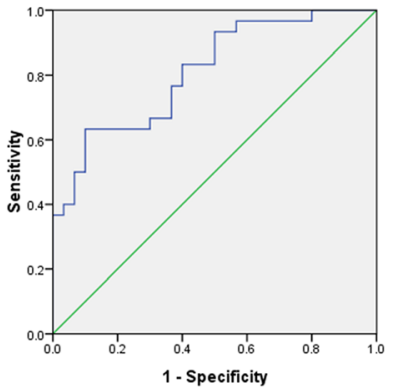

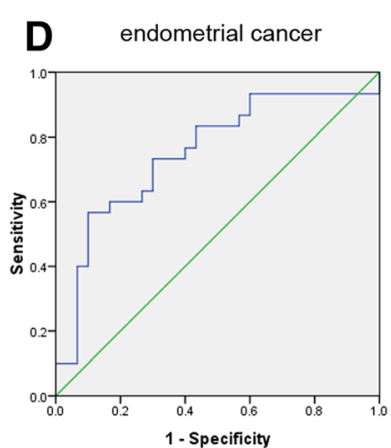

H hyroid cancer

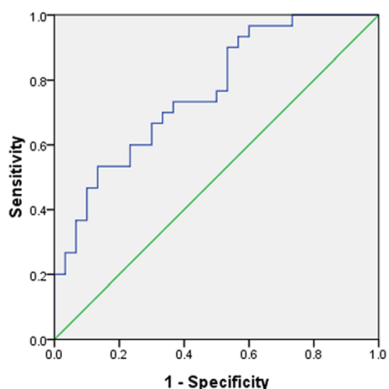

Fig. 1 The ROC analyses for serum BLACAT1 in discriminating 8 types of cancer from matched benign lesion. (a) bladder cancer; (b) cervical cancer; (c) esophagus cancer; (d) endometrial cancer; (e) gastric cancer; (f) hepatocellular carcinoma; (g) lung cancer; (h) hyroid cancer 
Table 1 BLACAT1 could act as a non-specific diagnostic biomarker for these common cancers

\begin{tabular}{|c|c|c|c|c|c|c|c|c|c|}
\hline \multirow[t]{2}{*}{ variable } & \multicolumn{3}{|c|}{ cancer vs benign } & \multicolumn{3}{|c|}{ cancer vs healthy } & \multicolumn{3}{|c|}{ benign vs healthy } \\
\hline & $p$-value & FC & AUC & $p$-value & FC & AUC & $p$-value & FC & AUC \\
\hline hepatocellular carcinoma & 0.01 & 2.4 & 0.7 & $<0.01$ & 5.3 & 0.878 & $<0.01$ & 2.2 & 0.891 \\
\hline lung cancer & $<0.01$ & 2.8 & 0.81 & $<0.01$ & 5.3 & 0.967 & 0.06 & 1.9 & - \\
\hline breast cancer & $<0.01$ & 1.8 & - & $<0.01$ & 2.9 & 0.864 & 0.04 & 1.6 & - \\
\hline ovarian cancer & $<0.01$ & 1.6 & - & $<0.01$ & 3.1 & 0.933 & $<0.01$ & 1.9 & - \\
\hline endometrial cancer & $<0.01$ & 2.2 & 0.751 & $<0.01$ & 6.6 & 0.932 & $<0.01$ & 2.9 & 0.987 \\
\hline cervical cancer & $<0.01$ & 2.6 & 0.782 & $<0.01$ & 5.9 & 0.963 & $<0.01$ & 2.3 & 0.891 \\
\hline prostate cancer & 0.111 & 1.6 & - & $<0.01$ & 4.1 & 0.833 & $<0.01$ & 2.6 & 0.827 \\
\hline gastric cancer & $<0.01$ & 2.6 & 0.808 & $<0.01$ & 4.5 & 0.933 & 0.02 & 1.7 & - \\
\hline esophagus cancer & $<0.01$ & 2.7 & 0.781 & $<0.01$ & 6.2 & 0.933 & $<0.01$ & 2.3 & 0.966 \\
\hline hyroid cancer & $<0.01$ & 2.1 & 0.762 & $<0.01$ & 2.9 & 0.933 & 0.76 & 1.4 & - \\
\hline bladder cancer & $<0.01$ & 2.9 & 0.722 & $<0.01$ & 4.7 & 0.833 & 0.047 & 1.6 & - \\
\hline nasopharynx cancer & 0.01 & 1.6 & - & $<0.01$ & 2.4 & 0.867 & $<0.01$ & 1.5 & - \\
\hline
\end{tabular}

$F C$ : fold-change; $p$ : $p$-value by students' $T$-test; AUC: Area under ROC curve

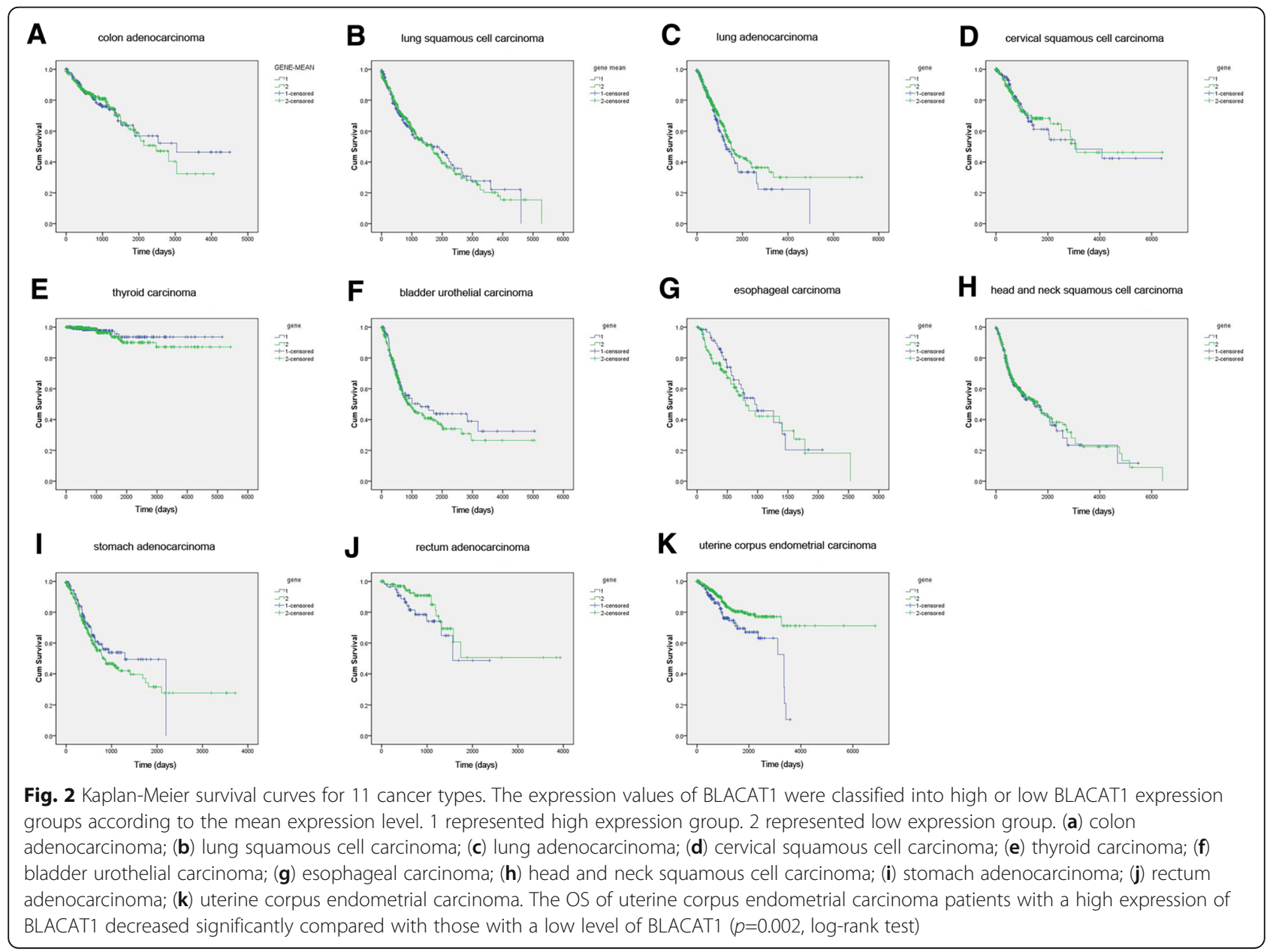


operating characteristic; STAD: Stomach adenocarcinoma; TC: Hyroid cancer; TCGA: The Cancer Genome Atlas; THCA: Thyroid carcinoma; UCEC: Uterine corpus endometrial carcinoma

\section{Acknowledgments}

Not applicable.

\section{Funding}

The work was funded by grant from the project of science and technology of Liuzhou, Guangxi, China (2014G020403).

\section{Availability of data and materials}

The datasets used and analyzed during the current study are available from the corresponding author on reasonable request.

\section{Authors' contributions}

$X C$ and MD wrote the manuscript. $\mathrm{XL}$ and $\mathrm{HZ}$ conducted all experiments and analyzed the data. JL, YH and ZH collected the samples and clinical data. JC and SD designed the project and supervised all experiments. All authors read and approved the final manuscript.

\section{Competing interests}

None.

\section{Publisher's Note}

Springer Nature remains neutral with regard to jurisdictional claims in published maps and institutional affiliations.

\section{Author details}

${ }^{1}$ Medical Science Laboratory, the Fourth Affiliated Hospital of Guangxi Medical University, Liuzhou, Guangxi 545005, China. ²Department of General Surgery, the Fourth Affiliated Hospital of Guangxi Medical University, Liuzhou, Guangxi 545005, China. ${ }^{3}$ No.1 LIUSHI Rd, Liuzhou city, Guangxi Province 545005, China.

\section{Received: 14 July 2017 Accepted: 28 September 2017}

Published online: 16 October 2017

\section{References}

1. Obort AS, Ajadi MB, Akinloye O. Prostate-specific antigen: any successor in sight? Rev Urol. 2013;15:97-107.

2. Liu L, Zhao Y, Jia J, Chen H, Bai W, Yang M, Yin Z, He C, Zhang L, Guo W, et al. The Prognostic Value of Alpha-Fetoprotein Response for Advanced-Stage Hepatocellular Carcinoma Treated with Sorafenib Combined with Transarterial Chemoembolization. Sci Rep. 2016;6:19851.

3. Jain P, Mondal SK, Sinha SK, Mukhopadhyay M, Chakraborty I. Diagnostic and prognostic significance of different mucin expression, preoperative CEA, and CA-125 in colorectal carcinoma: A clinicopathological study. J Nat Sci Biol Med. 2014:5:404-8.

4. Wolf AM, Wender RC, Etzioni RB, Thompson IM, D'Amico AV, Volk RJ, Brooks DD, Dash C, Guessous I, Andrews K, et al. American Cancer Society guideline for the early detection of prostate cancer: update 2010. CA Cancer J Clin. 2010; 60:70-98.

5. Liu Z, Zhang Y, Niu Y, Li K, Liu X, Chen H, Gao C. A systematic review and meta-analysis of diagnostic and prognostic serum biomarkers of colorectal cancer. PLoS One. 2014;9:e103910.

6. Reichl P, Mikulits W. Accuracy of novel diagnostic biomarkers for hepatocellular carcinoma: An update for clinicians (Review). Oncol Rep. 2016;36:613-25.

7. Nagano T, Fraser P. No-nonsense functions for long noncoding RNAs. Cell. 2011;145:178-81.

8. Ponting CP, Oliver PL, Reik W. Evolution and functions of long noncoding RNAs. Cell. 2009;136:629-41.

9. Kugel JF, Goodrich JA. Non-coding RNAs: key regulators of mammalian transcription. Trends Biochem Sci. 2012;37:144-51.

10. Prensner JR, Chen W, Iyer MK, Cao Q, Ma T, Han S, Sahu A, Malik R, Wilder-Romans $\mathrm{K}$, Navone N, et al. PCAT-1, a long noncoding RNA, regulates BRCA2 and controls homologous recombination in cancer. Cancer Res. 2014;74:1651-60.

11. lyer MK, Niknafs YS, Malik R, Singhal U, Sahu A, Hosono Y, Barrette TR, Prensner JR, Evans JR, Zhao S, et al. The landscape of long noncoding RNAs in the human transcriptome. Nat Genet. 2015;47:199-208.
12. Tang L, Zhang W, Su B, Yu B. Long noncoding RNA HOTAIR is associated with motility, invasion, and metastatic potential of metastatic melanoma. Biomed Res Int. 2013;2013:251098.

13. Ge XS, Ma HJ, Zheng XH, Ruan HL, Liao XY, Xue WQ, Chen YB, Zhang Y, Jia WH. HOTAIR, a prognostic factor in esophageal squamous cell carcinoma, inhibits WIF-1 expression and activates Wnt pathway. Cancer Sci. 2013;104: $1675-82$.

14. Zhang X, Zhang W, Cao WD, Cheng G, Zhang YQ. Glioblastoma multiforme: Molecular characterization and current treatment strategy (Review). Exp Ther Med. 2012;3:9-14.

15. Zheng S, Zheng D, Dong C, Jiang J, Xie J, Sun Y, Chen H. Development of a novel prognostic signature of long non-coding RNAs in lung adenocarcinoma. J Cancer Res Clin Oncol. 2017;

16. He B, Zeng J, Chao W, Chen X, Huang Y, Deng K, Huang Z, Li J, Dai M, Chen $S$, et al. Serum long non-coding RNAs MALAT1, AFAP1-AS1 and AL359062 as diagnostic and prognostic biomarkers for nasopharyngeal carcinoma. Oncotarget. 2017:8:41166-77.

17. Li X, Wang F, Sun Y, Fan Q, Cui G. Expression of long non-coding RNA PANDAR and its prognostic value in colorectal cancer patients. Int J Biol Markers. 2017;32:e218-23.

18. Nie ZL, Wang YS, Mei YP, Lin X, Zhang GX, Sun HL, Wang YL, Xia YX, Wang SK. Prognostic significance of long noncoding RNA Z38 as a candidate biomarker in breast cancer. J Clin Lab Anal. 2017;

19. Hu Y, Pan J, Wang Y, Li L, Huang Y. Long noncoding RNA linc-UBC1 is negative prognostic factor and exhibits tumor pro-oncogenic activity in gastric cancer. Int J Clin Exp Pathol. 2015;8:594-600.

20. He W, Cai Q, Sun F, Zhong G, Wang P, Liu H, Luo J, Yu H, Huang J, Lin T. Linc-UBC1 physically associates with polycomb repressive complex 2 (PRC2) and acts as a negative prognostic factor for lymph node metastasis and survival in bladder cancer. Biochim Biophys Acta. 2013;1832:1528-37.

21. Dai M, Chen X, Mo S, Li J, Huang Z, Huang S, Xu J, He B, Zou Y, Chen J, Dai S. Meta-signature LncRNAs serve as novel biomarkers for colorectal cancer: integrated bioinformatics analysis, experimental validation and diagnostic evaluation. Sci Rep. 2017;7:46572.

22. Harvey KF, Zhang X, Thomas DM. The Hippo pathway and human cancer. Nat Rev Cancer. 2013;13:246-57.

23. Pan D. The hippo signaling pathway in development and cancer. Dev Cell. 2010;19:491-505.

24. Mitamura T, Watari H, Wang L, Kanno H, Kitagawa M, Hassan MK, Kimura T, Tanino M, Nishihara H, Tanaka S, Sakuragi N. microRNA 31 functions as an endometrial cancer oncogene by suppressing Hippo tumor suppressor pathway. Mol Cancer. 2014;13:97.

25. Romero-Perez L, Garcia-Sanz P, Mota A, Leskela S, Hergueta-Redondo M, Diaz-Martin J, Lopez-Garcia MA, Castilla MA, Martinez-Ramirez A, Soslow RA, et al. A role for the transducer of the Hippo pathway, TAZ, in the development of aggressive types of endometrial cancer. Mod Pathol. 2015;28:1492-503.

26. Wang $C$, Jeong $K$, Jiang $H$, Guo W, Gu C, Lu Y, Liang J. YAP/TAZ regulates the insulin signaling via IRS1/2 in endometrial cancer. Am J Cancer Res. 2016;6:996-1010.

\section{Submit your next manuscript to BioMed Central and we will help you at every step:}

- We accept pre-submission inquiries

- Our selector tool helps you to find the most relevant journal

- We provide round the clock customer support

- Convenient online submission

- Thorough peer review

- Inclusion in PubMed and all major indexing services

- Maximum visibility for your research

Submit your manuscript at www.biomedcentral.com/submit
Biomed Central 